Jurnal Instruksional, Volume 1, Nomor 2, April $2020 \mid 172$ ISSN: $2686-5645$

\title{
PENGGUNAAN MULTIMEDIA DAN ANIMASI INTERAKTIF TERHADAP KETERAMPILAN MEMBACA PERMULAAN SISWA
}

\author{
Andriyani ${ }^{1)}$, Happy Indira Dewi ${ }^{2)}$, Zulfitria $^{3)}$ \\ ${ }^{1}$ KB-TK Lab School FIP UMJ Jl. K.H Ahmad Dahlan Ciputat Tangerang 15419 \\ email: bundaindri.yani80@gmail.com \\ ${ }^{2}$ Magister Teknologi Pendidikan, Universitas Muhammadiyah Jakarta \\ email: h.indiradewi@umj.ac.id \\ ${ }^{3}$ Magister Teknologi Pendidikan, Universitas Muhammadiyah Jakarta \\ email: fzulfitria@umj.ac.id
}

\begin{abstract}
The purpose of this study was to determine the effect of the use of multimedia and interactive animation on early reading skills in early childhood. This research was conducted at TK Lab School FIP UMJ and Kindergarten Ketilang which involved 60 students in TK B group. The research method was using experimental research design statistics with $2 \times 2$ treatment with level design. The results of the multiple regression statistical analysis prove that multimedia and interactive animation have positive and significant effects. This can be proven from the results of the multiple regression statistical analysis it is known that Multimedia has a positive and significant effect on Early Reading Skills, meaning that multimedia and animation together (simultaneously) affect early reading skills.
\end{abstract}

Keywords: multimedia, interactive animation, early reading skills

\begin{abstract}
Abstrak
Tujuan dari penelitian ini adalah untuk mengetahui pengaruh penggunaan multimedia dan animasi interaktif pada keterampilan membaca dini pada anak usia dini. Penelitian ini dilakukan di TK Lab School FIP UMJ dan TK Ketilang yang melibatkan 60 siswa kelompok TK B. Metode penelitian menggunakan statistik desain penelitian eksperimental dengan perlakuan $2 \times 2$ dengan desain level. Hasil analisis statistik regresi berganda membuktikan bahwa multimedia dan animasi interaktif memiliki efek positif dan signifikan. Hal ini dapat dibuktikan dari hasil analisis statistik regresi berganda diketahui bahwa Multimedia memiliki pengaruh positif dan signifikan terhadap Keterampilan Membaca Awal, artinya multimedia dan animasi secara bersama-sama (simultan) mempengaruhi keterampilan membaca awal.
\end{abstract}

Kata kunci: multimedia, animasi interaktif, keterampilan membaca awal

\section{PENDAhUluaN}

Guru anak usia dini didefinisikan sebagai tempat untuk mempersiapkan siswa memasuki masa sekolah yang dimulai di jenjang sekolah dasar. Kegiatan yang dilakukan dalam guruan anak usia dini pun hanyalah bermain dengan mempergunakan media pembelajaran. Seperti yang di tuliskan pada pasal 4 ayat 5 Sisdiknas disebutkan, guruan diselenggarakan dengan mengembangkan budaya membaca, menulis, dan berhitung bagi segenap warga masyarakat. Guruan yang dilakukan bisa merupakan perkembangan kemampuan bahasa anak salah satunya adalah mengajarkan siswa untuk membaca permulaan. Hasil studi Atifah Fauzia (2017) menunjukkan bahwa multimedia interaktif dapat meningkatkan kemampuan membaca permulaan dan layak dan efektif diterapkan bagi siswa. Pelajaran membaca tidak diperkenakan di tingkat guruan anak usia dini kecuali hanya pengenalan huruf-huruf dan angka-angka, itu pun dilakukan setelah anak-anak memasuki guruan tahap yang lebih tinggi. Salah satu langkah pertama untuk mengenalkan siswa membaca permulaan adalah belajar mengenal bentukbentuk huruf. 
Mengenalkan huruf bukanlah merupakan suatu tindakan alamiah dari seorang anak kerena kemampuan membaca permulaan pada seorang anak tidaklah didapatkan begitu saja seiring perkembangan usiannya. Untuk mendapatkan kemampuan mengenal huruf pada anak diperlukan suatu proses bermain seraya belajar. Lingkungan dan orang tua memegang peranan penting dalam proses pengenal huruf, yang pada awalnya akan ditangkap oleh siswa sebagai bahasa lisan. Membaca permulaan pada anak yaitu dengan melakukan pembelajaran sambil bermain menggunakan media pembelajaran yang menarik.

Persoalan membaca memang merupakan fenomena tersendiri. Kini menjadi semakin hangat dibicarakan para orang tua yang memiliki anak usia dini dan sekolah dasar kerena mereka khawatir anakanaknya tidak mampu mengikuti pelajaran di sekolah nanti jika sedari awal belum dibekali kemampuan membaca. Kekhawatiran orang tuapun semakin kuat ketika anak-anaknya belum bisa membaca menjelang masuk sekolah dasar. Hal itu membuat para orang tua akhirnya sedikit memaksa anaknya untuk belajar membaca.

Mencermati kondisi kegiatan pembelajaran membaca dan menulis di Taman Kanak-Kanak yang berlangsung saat ini, perlu dilakukan penelitian yang bersifat reflektif dengan melakukan tindakan tertentu yang direncanakan, dilaksanakan dan dievaluasi. Dengan serangkaian tindakan itu diharapkan dapat mengubah suasana pembelajaran ke arah pembelajaran yang lebih memungkinkan siswa terlibat secara aktif dan menyenangkan. Hal itu dapat dicapai dengan melalui multimedia dan animasi interaktif. Multimedia dan animasi interaktif adalah penyajian visual 4 dimensi yang dibuat berdasarkan unsur dan prinsip rancangan multimedia dan animasi interaktif yang berisi unsur kehidupan sehari-hari tentang manusia benda-benda, binatang, peristiwa, tempat dan sebagainya.
Multimedia dan animasi interaktif banyak digunakan guru sebagai teknologi dalam proses belajar mengajar, sebab menarik dan efektif, serta menambah gairah dalam motivasi belajar siswa.

\section{KAJIAN LITERATUR}

Belajar adalah proses perubahan tingkah laku dalam arti seluas-luasnya, meliputi: pengamatan, pengenalan, pengertian, pengetahuan, keterampilan, perasaan, minat penghargaan sikap (Sunarsih, 2007:3). Sedangkan menurut Gagne belajar merupakan kegiatan yang kompleks. Hasil belajar berupa kapabilitas. Setelah belajar, orang memiliki keterampilan, pengetahuan sikap dan nilai. Timbulnya kapabilitas tersebut adalah dari: (1) stimulus yang berasal dari lingkungan dan (2) proses kognitif yang dilakukan oleh pembelajar. (Dimyati dan Mudjiono, 2013:10).

Berdasarkan pendapat di atas dapat disimpulkan bahwa, belajar adalah kegiatan yang dilakukan melalui proses kognitif yang mengubah sifat stimulus lingkungan, melewati pengolahan informasi menjadi kapabilitas baru melalui pengamatan, pengenalan, pengertian, pengetahuan, perbuatan, keterampilan, perasaan, minat penghargaan sikap.

Media merupakan wadah dari pesan yang oleh sumber pesan ataupun penyalurannya yang diteruskan kepada sasaran atau penerima pesan tersebut. Aplikasi media pembelajaran berpijak pada kaidah ilmu komunikasi, yaitu "who says what, in which channels, to whom, in what effect". Yang berarti terdapat sumber pesan, media/channel yang digunakan, sasarannya siapa, dan pengaruh dari pesan tersebut (Situmorang, 2015:74). Selain pendapat tersebut, Prihatin menerangkan bahwa media pembelajaran adalah media yang dapat digunakan untuk membantu siswa di dalam memahami dan memperoleh informasi yang dapat didengar ataupun dilihat oleh panca indera sehingga 
pembelajaran dapat berhasil guna dan berdaya guna (Prihatin, 2008: 50).

Berdasarkan beberapa pendapat yang telah dikemukakan para ahli, peneliti menyimpulkan bahwa media pembelajaran adalah segala alat fisik yang digunakan oleh guru untuk menyampaikan materi kepada siswa guna merangsang siswa agar dapat belajar secara cepat, tepat, mudah, benar dan tidak terjadinya verbalisme sehingga tujuan pembelajaran dapat tercapai.

Fungsi dan manfaat media pembelajaran adalah memudahkan guru dalam proses pembelajaran yang memungkinkan terjadinya pengalaman belajar pada diri siswa dengan menggerakkan segala sumber belajar yang efektif dan efisien. Media yang ditampilkan diharapkan membuat siswa merasa tertarik terhadap materi yang diajarkan sehingga proses pembelajaran tidak terkesan membosankan. Dengan menggunakan media pembelajaran seperti video animasi dalam proses membaca permulaan pada siswa di TK Lab School FIP UMJ, diharapkan siswa akan termotivasi dan menimbulkan kegairahan belajar, membangkitkan keinginan dan minat baru terhadap proses membaca permulaan ada anak usia dini dan dapat memberikan pengalaman yang menyeluruh dari sesuatu yang konkret.

Media audio visual sering disebut dengan AVA, singkatan dari Audio Visual Aids, bisa diartikan alat pembantu atau alat peraga Audio Visual. Dalam pengertian yang luas, yang dimaksud dengan media audio visual meliputi semua alat peraga guruan yang dapat dilihat dan didengar. Media audio visual merupakan media yang dilengkapi fungsi suara dan gambar dalam satu unit, seperti film gerak (movie) bersuara, televisi, dan video. Media audio visual memiliki beberapa karakteristik antara lain:

1. Mengatasi keterbatasan jarak dan waktu.

2. Mampu menggambarkan peristiwa masa lalu secara realistis.
3. Dapat membawa siswa dari negara satu ke negara lain dan dari masa ke masa yang lain.

4. Dapat diulang bila perlu untuk menambahkan kejelasan.

5. Pesan yang disampaikan cepat dan mudah diingat.

6. Mengembangkan pikiran dan pendapat siswa.

7. Mengembangkan imajinasi.

8. Memperjelas hal-hal abstrak dan memberikan gambaran yang lebih konkret.

9. Sangat kuat mempengaruhi emosi seseorang.

10. Sangat baik menjelaskan suatu proses dan keterampilan.

11. Semua siswa dapat belajar dari film dan video, baik yang pandai maupun yang kurang pandai.

12. Menumbuhkan minat dan motivasi belajar.

13. Memberikan efek yang kuat terhadap penontonnya terutama terhadap perubahan sikap.

14. Dapat menghadirkan efek suara dan gambar sekaligus.

15. Menumbuhkan minat dan motivasi belajar.

16. Televisi: Memberikan kejadian-kejadian yang sebenarnya pada saat terjadi suatu peristiwa (real time) dengan disertai komentar penyiarnya.

17. Memperluas tinjauan kelas, melintas berbagai daerah atau berbagai negara.

18. Dapat menciptakan kembali masa lampau.

19. Dapat menunjukkan banyak hal dari banyak segi yang beranekan ragam.

20. Banyak mempergunakan sumber-sumber masyarakat.

21. Menarik minat siswa.

22. Dapat melatih guru baik dalam preservice maupun dalam in-service training. 
23. Masyarakat diajak berpartisipasi dalam rangka meningkatkan perhatian mereka terhadap sekolah.

24. Baik digunakan dalam pembelajaran mandiri dan jarak jauh.

Secara keseluruhan multimedia pembelajaran interaktif berarti suatu pembelajaran yang menggunakan komputer sebagai media dalam menyampaikan materi dengan menggabungkan teks, gambar, grafik, suara, animasi, dan video, serta dalam menyajikannya, siswa berinteraksi langsung dengan komputer untuk mendapatkan respon yang diinginkan.

\section{METODE PENELITIAN}

Penelitian ini bertempat di Taman Kanak-kanak Lab School FIP UMJ dan Taman Kanak-kanak Ketilang di kelompok B. Kelurahan Cirendeu, Kecamatan Ciputat Timur Tangerang Selatan. Pelaksanaan penelitian dilaksanakan pada semester ganjil di TK Lab School FIP UMJ dan TK Ketilang, Tangerang Selatan. Adapun waktu penelitiannya pada bulan November-Januari semester I dan II tahun ajaran 2018-2019.

Adapun desain yang digunakan dalam penelitian eksperimen ini adalah sebagai berikut: dengan rancangan treatment by level $2 \times 2$, dengan variabel terikat dalam penelitian ini adalah keterampian membaca permulaan sedangkan variabel bebasnya media pembelajaraan dengan kecerdasan membaca permulaan. Sebagai populasi dalam penelitian ini adalah seluruh siswa TK B di TK Lab School FIP UMJ dan TK B di TK Ketilang sebanyak 60 siswa.

\section{HASIL DAN PEMBAHASAN}

Berdasarkan hasil pengujian tes awal (pretes) tidak terdapat perbedaan yang signifikan pada kelas eksperimen dan kelas kontrol. Ini berarti bahwa pemilihan kelasnya berasal dari populasi yang homogen. Keadaan ini sangat membantu untuk melihat perkembangan keterampilan membaca permulaan siswa setelah pembelajaran berlangsung. Hasil analisis descriptive statistics menunjukkan peningkatan keterampilan membaca permulaan pada siswa, dimana dari rata-rata nilai pretest kelompok eksperimen mengalami peningkatan pada pretes sebesar 66.67 menjadi 78.83. Demikian pula halnya dengan kelas kontrol pada pretest diperoleh nilai rata-rata (mean) sebesar 65.33 meningkat menjadi 81.50. Hal ini dapat disimpulkan bahwa multimedia dan animasi interaktif mampu meningkatkan keterampilan membaca permulaan pada anak usia 5-6 tahun.

\section{Analisis Data Tes Awal (Pretest)}

Berdasarkan hasil pengolahan data hasil pretest kelas eksperimen dan kelas kontrol dalam penelitian ini, maka diperoleh statistik deskriptif yang terdiri dari nilai maksimum, nilai minimum, rata-rata, simpangan baku dan varians. diketahui bahwa pada kelas eksperimen dengan responden sebanyak 30 orang, diketahui nilai maksimum sebesar 85 , nilai minimum 50 , rata-rata 66.67 , memiliki simpangan baku 8.938, dengan varians 79.885. Sementara itu, kelas kontrol dengan responden sebanyak 30 orang diketahui nilai maksimum sebesar 80, nilai minimum 50, rata-rata 65.33, simpangan baku 8.087, dengan varians 65.402 .

Berdasarkan hasil output uji normalitas dengan menggunakan uji Shapiro-Wilk pada tabel 4.2 nilai signifikansi pada kolom signifikansi data nilai tes awal (pretest) untuk eksperimen adalah 0,58 dan kelas kontrol adalah 0,117. Karena nilai signifikansi kedua kelas lebih dari 0,05 , maka dapat dikatakan bahwa kelas kontrol dan kelas eksperimen berdistribusi normal.

Berdasarkan hasil output uji homogenitas varians dengan menggunakan uji Levene pada tabel 4.3 nilai signifikansinya (Based on Mean) adalah 0,770 . Karena nilai signifikansinya lebih dari 0,05 , maka dapat disimpulkan bahwa siswa kelas kontrol dan kelas eksperimen berasal 
dari populasi-populasi yang mempunyai varians yang sama, atau kedua kelas tersebut homogen.

Terlihat bahwa nilai signifikansi (sig.2tailed) dengan uji-t adalah 0,547. Karena nilai probabilitasnya lebih besar dari 0,05 maka H0 diterima atau keterampilan membaca permulaan siswa kelas eksperimen dan kelas kontrol pada tes awal (pretest) tidak berbeda secara signifikan

\section{Analisis Data Tes Akhir (Postest)}

Berdasarkan hasil pengolahan data hasil postest kelas eksperimen dan kelas kontrol, maka diperoleh statistik deskriptif nilai maksimum sebesar 90, nilai minimum 70 , rata-rata 78.83 , memiliki simpangan baku 6.524 dengan varians 42.557. Sementara itu, kelas kontrol dengan responden sebanyak 30 orang diketahui nilai maksimum sebesar 95, nilai minimum 70 , rata-rata 81.50 , simpangan baku 6.585, dengan varians 43.362 .

Hasil penelitian ini sejalan dengan penelitian Zulkifli Sidiq (2012), diketahui mean level pada fase intervensi (B) mengalami peningkatan jika dibandingkan dengan fase baseline 1 (Al), hal ini menunjukkan adanya peningkatan persentase kemampuan subjek dalam membaca permulaan dibandingkan data mean pada fase baseline 1 (Al). Sedangkan mean level pada fase baseline 2 (A2) mengalami penurunan jika dibandingkan dengan fase intervensi (B), meskipun demikian jika dilihat dari data mean pada tahap fase basline 2 (A2) anak menunjukan peningkatan dibandingkan data mean pada fase baseline $1(\mathrm{Al})$.

Berdasarkan hasil output uji normalitas dengan menggunakan uji Shapiro-Wilk pada tabel 4.6 nilai signifikansi pada kolom signifikansi data nilai tes akhir (postest) untuk eksperimen adalah 0,003 dan kelas kontrol adalah 0,023. Karena nilai signifikansi kedua kelas lebih kecil dari 0,05, maka dapat dikatakan bahwa kelas kontrol dan kelas eksperimen berdistribusi tidak normal.

Berdasarkan hasil output uji homogenitas varians dengan menggunakan uji Levene pada tabel 4.7 nilai signifikansinya (Based on Mean) adalah 0,476 . Karena nilai signifikansinya lebih dari 0,05, maka dapat disimpulkan bahwa siswa kelas kontrol dan kelas eksperimen berasal dari populasi-populasi yang mempunyai varians yang sama, atau kedua kelas tersebut homogen.

Berdasarkan hasil ouput diperoleh nilai sig. (2-tailed) sebesar $0.000<0.05$, maka sesuai dasar pengambilan keputusan dalam uji independen sampel t-test, maka dapat disimpulkan $\mathrm{H} 0$ ditolak dan $\mathrm{H} 1$ diterima, yang artinya bahwa terdapat perbedaan keterampilan membaca permulaan terhadap kelompok siswa yang belajar menggunakan multimedia dan memiliki keterampilan bahasa tinggi dengan kelompok siswa yang belajar menggunakan animasi interaktif dan memiliki keterampilan bahasa tinggi.

Berdasarkan hasil output di atas, didapat nilai $\mathrm{r}^{2}$ ( $\mathrm{r}$ square) sebesar 0.835 atau $83.5 \%$, yang berarti multimedia dan animasi interaktif mempengaruhi keterampilan membaca permulaan sebesar $83.5 \%$ sedangkan sisanya sebesar $16.5 \%$ dipengaruhi oleh faktor lain di luar variabel penelitian ini. Hasil penelitian ini sejalan dengan penelitian Atifah Fauziah (2017) menunjukkan bahwa multimedia interaktif dapat meningkatkan kemampuan membaca permulaan. Demikian pula dengan penelitian Khansa (2018), diketahui penggunaan multimedia video interaktif berpengaruh signifikan terhadap keterampilan berbicara.

Hasil analisis statistic regresi berganda membuktikan bahwa multimedia dan animasi interaktif memiliki pengaruh yang positif dan signifikan baik secara parsial maupun simultan. Hal ini dapat dibuktikan dari hasil analisis statistic regresi berganda diketahui Multimedia berpengaruh positif dan signifikan terhadap Keterampilan 
Membaca Permulaan diperoleh thitung $>\mathrm{t}$ tabel $(6.185>2.000)$ dengan nilai signifikan $0.000<0,05$. Demikian pula halnya dengan pengaruh Animasi Interaktif terhadap Keterampilan Membaca Permulaan diperoleh $\mathrm{t}$ hitung $>\mathrm{t}$ tabel $(4.467>2.000)$ dengan nilai signifikan $0,000<0,05$.

Hasil penelitian ini sejalan dengan penelitian Elizabeth Eka Sulistyawati (2016), diketahui proses pembelajaran melaui media Video Compact Disk dapat meningkatkan kemampuan membaca permulaan. Sementara itu, secara simultan hasil penelitian membuktikan terdapat pengaruh positif dan signifikan menggunakan uji $\mathrm{F}$ diketahui Fhitung $>$ Ftabel $(65.521>2.76)$ dengan nilai signifikan sebesar $0,000<0,05$ atau 5\%,maka dapat disimpulkan Ho ditolak Ha diterima, artinya multimedia dan animasi interaktif secara bersama-sama (simultan) berpengaruh terhadap keterampilan membaca permulaan. Hasil penelitian ini sejalan dengan penelitian Zulkifli Sidiq (2012), diketahui penggunaan multimedia cerdas belajar baca dapat meningkatkan kemampuan membaca permulaan anak.

\section{KESIMPULAN}

Berdasarkan hasil penelitian dan analisis, maka dapat ditarik beberapa kesimpulan guna menjawab tujuan penelitian sebagai berikut:

1. Tidak terdapat perbedaan kemampuan membaca permulaan anak usia dini antara siswa yang diberikan multimedia dan siswa yang diajarkan menggunakan animasi interaktif. Hal ini dibuktikan hasil uji $t$ diketahui nilai signifikansi (sig.2-tailed) sebesar 0,121. Karena nilai probabilitasnya lebih besar dari 0,05 maka $\mathrm{H} 0$ diterima dan $\mathrm{Ha}$ ditolak.

2. Hasil analisis statistik regresi berganda membuktikan bahwa multimedia dan animasi interaktif memiliki pengaruh positif dan signifikan baik. Hal ini dapat dibuktikan dari hasil analisis statistic regresi berganda diketahui Multimedia berpengaruh positif dan signifikan terhadap Keterampilan Membaca Permulaan diperoleh $\mathrm{t}$ hitung $>\mathrm{t}$ tabel $(6.185>2.000)$ dengan nilai signifikan $0.000<0,05$. Demikian pula halnya dengan pengaruh Animasi Interaktif terhadap Keterampilan Membaca Permulaan diperoleh $\mathrm{t}$ hitung $>\mathrm{t}$ tabel $(4.467>2.000)$ dengan nilai signifikan $0,000<0,05$.

3. Secara simultan hasil penelitian membuktikan terdapat pengaruh positif dan signifikan menggunakan uji $\mathrm{F}$ diketahui Fhitung $>$ Ftabel (65.521 > 2.76) dengan nilai signifikan sebesar $0,000<0,05$ atau 5\%, maka dapat disimpulkan Ho ditolak Ha diterima, artinya multimedia dan animasi interaktif secara bersama-sama (simultan) berpengaruh terhadap keterampilan membaca permulaan.

Hasil penelitian ini membuktikan bahwa media pembelajaran multimedia dan animasi interaktif mampu meningkatkan keterampilan membaca permulaan siswa usia 5-6 tahun. Berdasarkan kesimpulan di atas, maka dapat diberikan beberapa saran sebagai berikut:

1. Bagi sekolah

Diharapkan pihak manajemen sekolah mampu meningkatkan fasilitas sarana dan prasana guna meningkatkan efektivitas pembelajaran di sekolah.

2. Bagi guru

Diharapkan bagi para guru terus berupaya mengembangkan media pembelajaran sesuai dengan kebutuhan informasi dan perkembangan teknologi agar kegiatan pembelajaran lebih aktif dan hasilnya lebih efektif sesuai harapan bersama.

3. Bagi penulis

Diharapkan mengembangkan variabel penelitian ke depannya dimensi agar hasil penelitian lebih bervariasi dan akurat. 
Jurnal Instruksional, Volume 1, Nomor 2, April $2020 \mid 178$ ISSN: 2686-5645

\section{REFERENSI}

Aisyah, Nyimas, dkk. Pengembangan Pembelajaran Matematika SD. 2007. Jakarta: Dirjen Dikti Departemen Guruan Nasional.

Al-Qur'an, Mushaf. Al-Qur'an dan Terjemahan. Jakarta: Pustaka Al-Kautsar.

Akhadiah, Sabarti., dkk. Pembinaan Kemampuan Menulis Bahasa Indonesia. 2004. Jakarta: Erlangga.

Andaru Mahardika, dan Henny Destiana. Animasi Interaktif Pembelajaran Pengenalan Hewan Dan Alat Transportasi Untuk Siswa Taman Kanak-Kanak. 2014. Jurnal Pilar Nusa Mandiri Vol.X No.1, Maret 2014.

Ansharullah. Guruan Islam Berbasis Kecerdasan Jamak: Multiple Intelligences. 2013. Jakarta: STEP.

Aqib, Zainal. Model-model, Media, dan Strategi Pembelajaran Kontekstual (Inovatif). 2013. Bandung: Yrama Widya.

Arifah, Hanif Nurul. Pengembangan Multimedia Pembelajaran Interaktif Keterampilan Membaca Permulaan Siswa Disleksia Kelas III SDN Bangunrejo II Yogyakarta. Jurnal Prodi Teknologi Guruan Vol. VI Nomor 6 Tahun 2017.

Arikunto, Suharsimi, Dasar-dasar Evaluasi Guruan, 2013. Jakarta: PT. Bumi Aksara.

Arikunto, Suharsimi, Prosedur Penelitian, 2013. Jakarta: PT. Bumi Aksara.

Arsyad, Azhar. Media Pembelajaran. 2013. Jakarta: Rajagrafindo Persada.

Azwar, Saifuddin, Metode Penelitian, 2005. Yogyakarta: Pustaka Pelajar.
Budiningsih, Asri. Belajar dan Pembelajaran. 2005. Jakarta: Rineka Cipta.

Budiyono. Statistika Dasar untuk Penelitian. 2004. Surakarta: FKIP UNS Press

Chalidah, Siti, Ellah. Terapi Permainan Bagi Anak yang Memerlukan Layanan Guruan Khusus. 2005. Jakarta: Departemen Guruan Nasional.

Daryanto. Media Pembelajaran. 2011. Bandung: Sarana Tutorial Nurani Sejahtera.

Depdiknas. Kamus Besar Bahasa Indonesia Edisi Keempat. 2008. Jakarta: PT Gramedia Pustaka Utama.

Dimyati. Mudjiono. Belajar dan Pembelajaran. 2013. Jakarta: Rineka Cipta.

Fauziah, Atifah. Multimedia Interaktif untuk Meningkatkan Kemampuan Membaca Permulaan Siswa Tunagrahita. Jurnal Ortopedagogia Volume 3 Nomor 1 Juli 2017.

Furth, Borko. Multimedia Tools and Applications. 1996. London: Kluwer Academic Publisher.

Hafiz, Ahmad Aziz. Kenapa Komik Digital; Indonesia ICT Award 2009. (https://www.academia.edu/1721061/Kenap a_Komik_Digital diakses pada tanggal 29 Desember 2018).

Hanafiah, Nanang dan Cucu, Suhana. Konsep Strategi Pembelajaran. 2010. Bandung: Refika Aditama.

Ibrahim, Muslimin. Pembelajaran Kooperatif, 2001. Surabaya: UNESA Press.

Indriana, Dina. Ragam Alat Bantu Media Pengajaran. 2011. Jogjakarta: Diva Perss.

Isjoni, Cooperative Learning. 2007. Bandung: CV. Alfabeta. 
Island, Script. Panduan Mudah Membuat Animasi. 2008. Jakarta: Media Kita.

Jamaris, Martini. Perkembangan dan Pengembangan Anak Usia Taman Kanakkanak. 2006. Jakarta: Gramedia.

Jerrold E. Kemp, dkk, Planning and Producing Instructional Media. 1985. New York: Harper and Row Publishers.

Khansa Alfreda Salsabila dan Wagino. Video Multimedia Interaktif Terhadap Keterampilan Berbicara Anak Tunarungu TKLB-B. Jurnal Guruan Khusus, 2018.

Lie, Anita, Cooperative Learning (Mempraktekan Cooperative Learning Di Ruang-Ruang Kelas). 2002. Jakarta: Grasindo.

M. Ramli. Media Pembelajaran Dalam Perspektif Al-Qur'an Dan Al-Hadits. Ittihad Jurnal Kopertais Wilayah XI Kalimantan Volume 13 No.23 April 2015.

MadComs, Aplikasi Animasi Digital. 2006. Jakarta: Andi.

Miarso, Yusufhadi. Menyemai Benih Teknologi Guruan. 2004. Jakarta: Prenada Media.

Mohan, Kisari Ganguli, Mahabharata, Buku 5: Udyoga Parwa: Bhagawata Yana Parwa: bagian CXXXI. 2006.

Morgan, G. \& Shade, D. 1994. Moving early chilhood education into the 21 st century. In. J.L. Wright, \& D.D. Shade (Eds.), Young children: Active learners in a technological age. Washinton, D.C.: National Association for the Education of Young Children.

Mudlofir, Ali dan Rusydiyah, Evi Fatimatur. Desain Pembelajaran Inovatif dari Teori ke
Praktik. 2016. Jakarta: PT RajaGrafindo Persada.

Munadi, Yudhi. Media Pembelajaran. Sebuah Pendekatan Baru. 2008.Jakarta: Gaung Persada Press.

Naga, Dali, S. Pengantar Teori Sekor Pada Pengukuran Guruan, 1992. Jakarta: Gunadarma.

Novan, Ardy, Wiyani. Psikologi Perkembangan Anak Usia Dini. 2014. Yogyakarta:Gava Media.

Patrisius P, Pengaruh Penggunaan Multimedia Pembelajaran Dan Motivasi Belajar Terhadap Hasil Belajar Membaca Text Report Siswa SMP. 2016. Tesis. Pascasarjana Teknologi Guruan, FKIP Universitas Tanjungpura, Pontianak.

Peraturan Menteri Guruan Dan Kebudayaan Republik Indonesia Nomor 137 Tahun 2014 Tentang standar Nasional Guruan Anak Usia Dini.

Peraturan Pemerintah (PP) No 17/2010 tentang Pengelolaan dan Penyelenggaraan Guruan.

Permendiknas No. 58 tahun 2009 tentang Standar Guruan Anak Usia Dini.

Pertiwi, Adharina, Dian. Study Deskriptif Proses Membaca Permulaan Anak Usia Dini. Pascasarjana Universitas Negeri Yogyakarta. Jurnal Guruan Anak, Volume 5, Edisi 1, Juni 2016.

Plomp, Tjeerd dan Donald P. Ely, 1996. International Encyclopedia of Educational Technology. Great Britain: Cambridge UniversityPress.

Pramono, Gatot. Aplikasi Component Display Theory dalam multimedia dan web pembelajaran. 2006. Departemen Guruan 
Nasional Pusat Teknologi Informasi dan Komunikasi Guruan.

Prihatin, Eka. Guru Sebagai Fasilitator. 2008. Bandung: Karsa Mandiri Persada.

Ramelan, Purwanti, Mendeteksi Menggali, Melatih, Serta Melejitkan Kecerdasan Buah Hati, Merangsang IQ Anak 4-9 tahun Dosis

Tinggi, 2010. Yogyakarta: Pustaka Widyatama.

Ramli. Pendampingan Perkembangan Anak Usia Dini. 2005. Jakarta: Depdiknas.

Ramli. M. Media Pembelajaran Dalam Perspektif Al-Qur'an Dan Al-Hadits. Ittihad Jurnal Kopertais Wilayah XI Kalimantan Volume 13 No.23 April 2015.

Reigeluth, C. Elaborating the elaboration theory. 1992. Educational Tchnology Research and Development 40:3.

Rianto, Yatim. Paradigma Baru Pembelajaran, 2009. Jakarta: Prenada Media.
Roblyer, M.D., dan Doering, A.H. Integrating Educational Technology Into Teaching. Boston: Pearson Educational, inc.

Salsabila, Alfreda, Khansa. Video Multimedia Interaktif Terhadap Keterampilan Berbicara Anak Tunarungu TKLB-B. Universitas Negeri Surabaya Fakultas Ilmu Pendidikan Jurusan Pendidikan Luar Biasa. Jurnal. 2018.

Sidiq, Zulkifli. Penggunaan Multimedia Interaktif Cerdas Belajar Baca dalam Meningkatkan Kemampuan Membaca Permulaan pada Anak Tunagrahita Ringan. Jurnal JASSIAnakku Volume 11: Nomor 1 Tahun 2012

Sulistiyawati, Eka, Elizabeth. Peningkatan Kemampuan Membaca Permulaan Melalui Media Video Compact Disc Pada Anak Usia 5-6 Tahun. Jurnal Pendidikan dan Pemberdayaan Masyarakat Volume 3 Nomor 1, Maret 2016. 